Introduction to the Guest Editor

\section{Edward M. Reece, MD, MBA}

\author{
Larry H. Hollier, Jr., MD, FACS, FAAP 1 \\ ${ }^{1}$ Division of Plastic Surgery, Baylor College of Medicine, \\ Houston, Texas \\ Semin Plast Surg 2018;32:155-156.
}

I want to thank my colleague Dr. Reece for serving as a guest editor for this edition. We also appreciate the efforts made by each outstanding author for contributing to this issue.

Edward M. Reece, MD, MBA, is an Associate Professor of surgery in the Division of Plastic Surgery at Baylor College of Medicine, Houston, Texas. He serves as the Chief of Adult Plastic Surgery-Baylor College of Medicine.

Dr. Reece received his MD, MBA from Case Western Reserve University and completed his postdoctoral fellowship training in general surgery and plastic surgery in the University of Texas at Southwestern Medical School. He has also completed a hand surgery fellowship at the University of Texas San Antonio and The Hand Center of San Antonio.

Combining technology and technique, Dr. Reece strives to elevate compassionate care with cutting edge medical breakthroughs. He offers advanced hand and reconstructive surgery options to children with injuries and congenital diseases, focusing on nerve surgery, free tissue transfer, and progressive reconstructions. Dr. Reece's research interests focus on peripheral nerves and reconstructive surgeries and on telehealth as it relates to improving doctor-patient interactions and coordinating efficient care and affordable cost.
Address for correspondence Larry H. Hollier, Jr., MD, FACS, Division of Plastic Surgery, Baylo College of Medicine, TCH Clinical Care Center, 6701 Fannin Street, Suite 610, Houston, TX 77030 (e-mail: larryh@bcm.tmc.edu).
Issue Theme Business and Technology; Guest Editor: Edward M. Reece, MD, MBA

(1)

Copyright (C) 2018 by Thieme Medical Publishers, Inc., 333 Seventh Avenue, New York, NY 10001, USA. Tel: +1(212) 584-4662.
DOI https://doi.org/

10.1055/s-0038-1673336. ISSN 1535-2188. 